\title{
CHANGES IN GAS BUBBLE DISEASE SIGNS AND SURVIVAL OF MIGRATING JUVENILE SALMONIDS EXPERIMENTALLY EXPOSED TO SUPERSATURATED GASSES
}

\section{ANNUAL REPORT 1996}

\author{
BY \\ Bruce H. Monk \\ Randall F. Absolon \\ and \\ Earl M. Dawley
}

\author{
Research funded by \\ Bonneville Power Administration \\ Contract Number 96-AI-93 892 \\ Project Number 96-24 \\ and \\ Coastal Zone and Estuarine Studies Division \\ Northwest Fisheries Science Center \\ National Marine Fisheries Service \\ National Oceanic and Atmospheric Administration \\ 2725 Montlake Boulevard East \\ Seattle, Washington 98 112-2097
}

November 1997 


\section{EXECUTIVE SUMMARY}

Two important questions remain regarding the effectiveness of biological monitoring to evaluate gas bubble disease (GBD) impacts on juvenile salmonids: 1) Do GBD signs change as a result of changing hydrostatic pressures experienced by juvenile salmonids during passage through turbine intakes, gatewells, and bypass conduits at dams? 2) Do physical detriments from GBD cause a decrease in survival resulting from direct or indirect effects such as predation during migration through reservoirs?

In response to these questions, we conducted research in 1996 to evaluate 1) changes in GBD signs in juvenile salmonids resulting from passage through turbine intakes and bypass systems, and 2) relative survival during migration through the lower Snake River for juvenile salmonids experimentally exposed to supersaturation of dissolved gas.

To meet these objectives, hatchery steelhead were captured at Little Goose and Lower Granite Dams, marked with passive integrated transponder (PIT) tags, and then experimentally exposed to supersaturated dissolved gas (averaging 113-1 17\% of saturation) for about 54 hours. Exposure was terminated when mortality reached 5 to $10 \%$. Resulting prevalence of GBD signs among treatment fish varied from 23 to $51 \%$, averaging $37.6 \%$.

After exposure, test fish were individually evaluated for signs of GBD. Seven replicates of 300 test and control fish (treated identically to test fish except not exposed to dissolved gas supersaturation) were then released about $400 \mathrm{~m}$ upstream from Little Goose Dam. Two additional groups of test fish were released directly in front of the turbine intake. About $38 \%$ of the treatment and control fish were automatically collected by a PIT-tag selector gate as 
they passed through the juvenile fish bypass system at Little Goose Dam (average time from release to recapture ranged from 3.3 to 10.1 hours). Each recovered fish was anesthetized and reexamined for signs of GBD. Changes in signs attributable to time spent in the forebay, prior to dam passage, were assessed using additional groups of experimentally exposed fish that were held in a net-pen in the forebay at Little Goose Dam. Estimates of relative survival differences between test and control fish groups were obtained from PIT-tag interrogations at Little Goose, Lower Monumental, and McNary Dams during migration.

Of test fish that displayed external GBD signs (subdermal emphysema on fins and opercula) when released, about $47 \%$ no longer had signs at recovery following migration to the dam, and passage through the turbine intake and the juvenile bypass system. The percentages of fish that lost GBD signs varied directly with, but were only mildly correlated to forebay TDG levels. Of test fish displaying no GBD signs at release, $5.9 \%$ showed GBD signs at re.covery. The control fish that displayed no GBD signs when released had a $3.8 \%$ prevalence of GBD signs at recovery.

In test fish recovered displaying GBD signs, average severity of signs decreased somewhat, from 1.5 to 1.2 index units (183 fish decreased, 407 no change, and 27 increased). Following experimental exposure to supersaturation, test fish often had GBD signs that were more severe than those commonly seen on juvenile salmonids examined from the river. Thus, we segregated data to examine changes occurring throughout the range of severity. Generally, fish displaying minor GBD signs at release ( 20\% emphysema coverage and less than 1-mm-diameter bubbles of one fin or operculum), showed a slight increase in severity of 
GBD signs at recovery. Fish with greater severity of GBD signs showed progressively decreased severity at reexamination.

Among fish held in the net-pens, only about $22 \%$ had lost GBD signs at reexamination (range of times similar to recovery times of forebay released fish), or about half of the loss observed among fish passing into and through the bypass system. Of the treatment fish displaying no GBD signs at entry to the net-pen, 8.1\% showed GBD signs after holding (similar to fish passing into and through the bypass system), although generally the severity of those signs was minor. Control fish were not held in the net-pen. Average severity of GBD signs decreased 0.2 index units (69 fish decreased, 73 no change, and 46 increased). As with free-swimming test fish, those displaying minor GBD signs showed a slight increase of sign severity. Fish with greater severity of signs showed progressively decreased severity at reexamination. Changes in severity were directly, but only mildly correlated with dissolved gas levels in the forebay.

No statistical difference in survival was observed for GBD-challenged steelhead compared with unchallenged counterparts, either at passage through Little Goose Dam or at passage through the other dams. downstream.

Additional tests are necessary to separate the effects of hydrostatic pressure during dam passage from the effects of depth distribution during reservoir residence on GBD signs. To conduct such tests, quicker recovery of fish passing through the dam will be necessary.

Because fish size may be of significant importance in rate of predation, smaller juvenile salmon must be used in a similar GBD challenge test to confirm that survival is not decreased in the smaller fish. Exclusive use of juvenile steelhead for these tests may have resulted in a 
conservative estimate for decreases in survival associated with a GBD insult during migration. Recent results from laboratory tests of juvenile salmon suggested greater predation by northern squawfish (Ptychocheilus oregonensis) on fish exposed to dissolved gas supersaturation than on unexposed cohorts (Matthew Mesa, USGS-Biological Resource Division, Cook Wash., Pers. corm-nun., March, 1996). However, compared with juvenile salmon migrants, the greater size and speed of steelhead likely decreases predation by fish and birds. Prey consumption data for northern squawfish in John Day Reservoir described by Poe et al. (1988) support this speculation for piscivores. 


\section{CONTENTS}

EXECUTIVE SUMMARY $\ldots, \ldots \ldots \ldots \ldots \ldots \ldots \ldots \ldots \ldots \ldots \ldots$

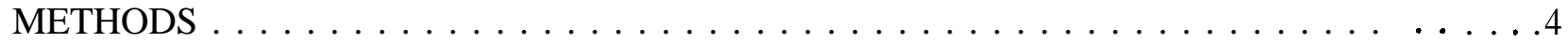

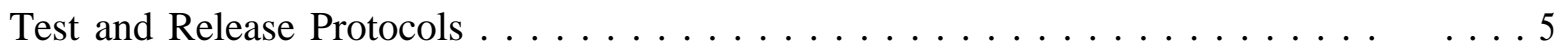

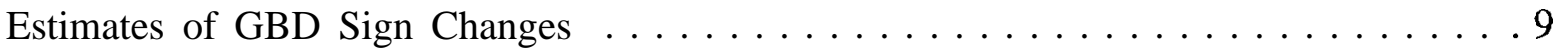

Estimates of Relative Survival of Supersaturation Challenged Fish . . . . . . . . 10

R E S U L T S . . . . . . . . . . . . . . . . . . . . . . . 1

Fish Released Into Forebay $\ldots \ldots \ldots \ldots \ldots \ldots \ldots$

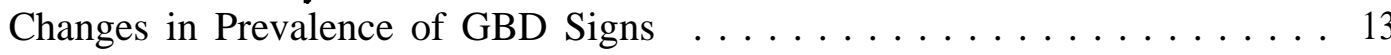

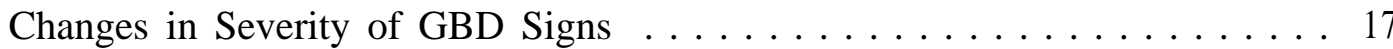

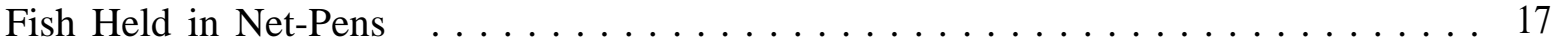

Changes in Relative Survival During Migration $\ldots \ldots \ldots \ldots \ldots \ldots$

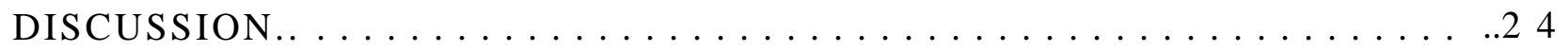

CONCLUSIONS AND RECOMMENDATIONS ................ 26

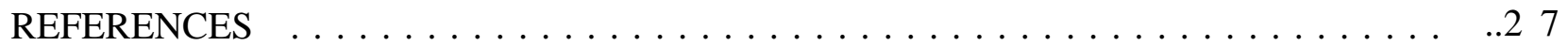




\section{INTRODUCTION}

Since the early 1960s, it has been well documented that spill at Snake and Columbia River dams increases total dissolved gas (TDG) levels, and that exposure to these higher levels causes gas bubble disease (GBD) and ensuing increased mortality to migrating juvenile salmonids (Oncorhynchus spp.). From 1966 to 1975, estimates of mortality to juvenile salmonids from the Snake River ranged from 40 to $95 \%$, and a major proportion of that mortality during high flow years was attributed to GBD (Ebel et al. 1975). In the last several years, higher spring flows, a reduced hydraulic capacity at some Snake River dams (caused by unit outages for repair or research), and efforts to achieve flood control elevations at storage reservoirs have required increased levels of spill. This has increased the TDG to levels approaching $140 \%$, well above the current state limit for TDG of $120 \%$, and has prompted concern that juvenile migrants might again be suffering undetected losses from GBD. Because of this concern, the Gas Bubble Trauma Monitoring Program was initiated in 1994 as part of the Fish Passage Center's Smolt Monitoring Program. Under the new program, a percentage of smolts monitored for physical condition are also monitored for GBD.

Two important questions remain regarding the effectiveness of biological monitoring to evaluate GBD impacts to juvenile salmonids on the Columbia and Snake Rivers: 1) Do signs of GBD change as a result of changing hydrostatic pressures experienced by juvenile salmonids during their passage through turbine intakes, gatewells, and bypass conduits of dams (Fig. 1)? 2) Do physical detriments from GBD cause a decrease in survival resulting from direct or indirect effects, such as predation, during migration through reservoirs? 


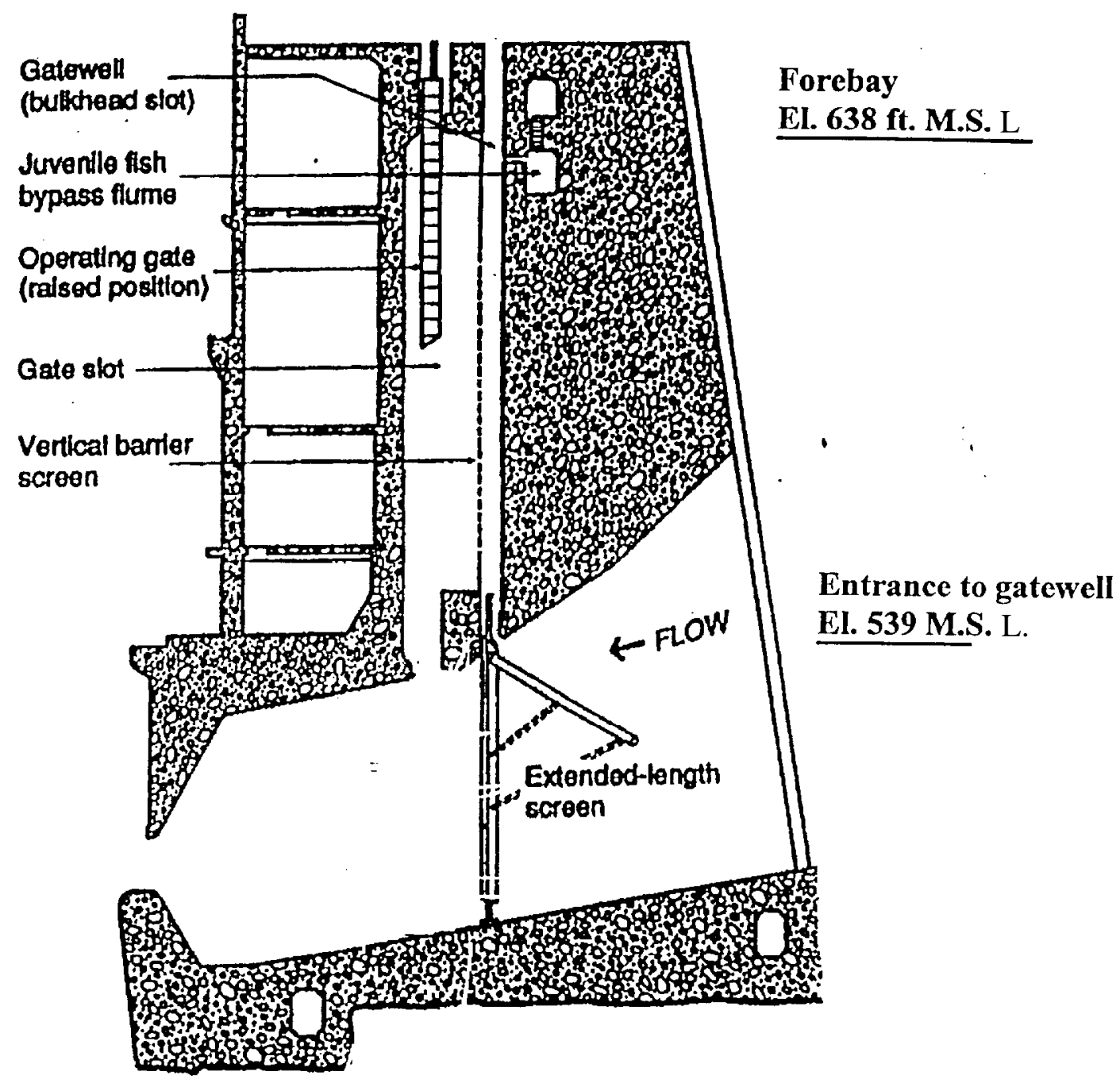

Figure 1. Cross section of turbine intake at Little Goose Dam, showing migration route of fish through intake, gatewell, and into the juvenile bypass. 
The suggestion that signs of GBD on juvenile salmon disappeared because of high hydrostatic pressures encountered during entry to the bypass systems at Columbia and Snake River dams was made by Dr. Larry Fidler in a letter to R. Ted Bottiger of the Northwest Power Planning Council, Portland, Oregon (November 23, 1994) . The Inspection Team of the Gas Bubble Disease Technical Work Group (GBDTWG 1995), and later the NMFS Panel on Gas Bubble Disease (1996), documented their concerns that estimates of GBD prevalence made at mainstem dams may not be representative for run-of-the-river juvenile salmonids. As a result of this potential flaw in the monitoring program, empirical evidence was sought to support or refute the premise of GBD-sign loss.

Results of laboratory investigation by Montgomery Watson (1995) documented rapid reabsorption of gas emboli in the gills and lateral lines of juvenile chinook salmon following pressurization. However, for emphysema within fin tissues, which constitute the signs used as the primary index of GBD at smolt sampling sites on the river, changes were much less pronounced. Additionally, the loss of signs reported for test fish in laboratory conditions do not necessarily represent effects on feral smolts migrating through the hydropower system. Durations of exposure to high pressure at the dam are unknown and may be quite variable in association with differences in the behavioral responses of smolts to the variable water currents and traveling screens encountered during passage through the turbine intakes.

To address these concerns, we studied the impacts of experimentally induced GBD on juvenile steelhead (0. mykiss) migrating through the Snake River in 1996. The two main objectives of this study were 1) to determine whether juvenile steelhead with experimentally induced signs of GBD retain the same prevalence of signs following passage through the 
juvenile fish bypass system at Little Goose Dam, and 2) to determine whether survival rates through the lower Snake River are different for juvenile salmonids with experimentallyinduced signs of GBD.

\section{METHODS}

From May 15 to June 9, nine replicate tests were conducted at Little Goose Dam using run-of-the-river hatchery steelhead. Fish were marked with passive integrated transponder (PIT) tags and then exposed to supersaturated dissolved gas. Prior to the occurrence of substantial mortality, and when a large proportion of test fish showed signs of GBD, test and control fish were individually examined and GBD signs recorded. Groups were then released into the forebay of Little Goose Dam and subsequently recovered in the bypass/collection facility for reexamination and to document changes in GBD signs resulting from dam passage. Changes in GBD signs attributable to time spent in the forebay, prior to dam passage, were assessed using additional groups of experimentally exposed fish that were held in a net-pen in the forebay at Little Goose Dam. Estimates of relative survival differences between test and control fish groups were obtained from PIT-tag interrogations at Little Goose, Lower Monumental, and McNary Dams during migration.

Prior to these tests, PIT-tag separation by code equipment, similar to that in use at Lower Granite Dam, was installed in the juvenile fish bypass/collection facilities downstream from the main PIT-tag detector slide gates at Little Goose Dam. This enabled the recapture of PIT-tagged test and control fish that entered the facility from the collection channel. To measure the changes in prevalence and severity of GBD, test and control fish were diverted 
into a holding tank where they were anesthetized, transferred to the examination facility, and reexamined for GBD (Fig. 2).

\section{Test and Release Protocols}

Steelhead for this study were obtained from the bypass/collection facilities at Little Goose Dam (Replicates 1, 2, and 4) and Lower Granite Dam (Replicates 3 and 5-9). Average weight of these fish was 75 grams. For each test replicate, fish were anesthetized, PIT tagged, and divided into a control group of 300 and a treatment group of 450. Both groups were held in 0.46 -m-deep 1,100-L circular tanks at a density of $29.8 \mathrm{~g} / \mathrm{L}$. Water was supplied from the Little Goose Dam forebay at $15 \mathrm{~L} /$ minute. The circular tanks were divided into quarters, with test fish held in all 4 quarters of the test tanks and control fish held in 3 of the 4 quarters, so that densities were similar in all tank quarters. For the nine replicates, water temperature ranged from 11.2 to 12.7 " C.

Dissolved gas levels in both test and control tanks required manipulation for these tests. To lower the TDG levels in the control tanks, water from the forebay was filtered through plastic packing aggregate Jaeger Rings.' Average TDG levels in these tanks ranged from 101.5 to $103.5 \%$ of saturation. In the treatment tanks, total dissolved gas levels were increased by the introduction of compressed atmospheric air through gas-permeable hollow fiber membranes at a pressure of $2.5-3.0 \mathrm{~kg} / \mathrm{cm}^{2}$. Inflow water was passed over the hollow membranes and through 3-4 $\mathrm{m}$ of $1.9-\mathrm{cm}$-diameter hose to the holding tanks. Average

1 Jaeger Rings are a commercial product; reference here is not an endorsement by National Marine Fisheries Service. 


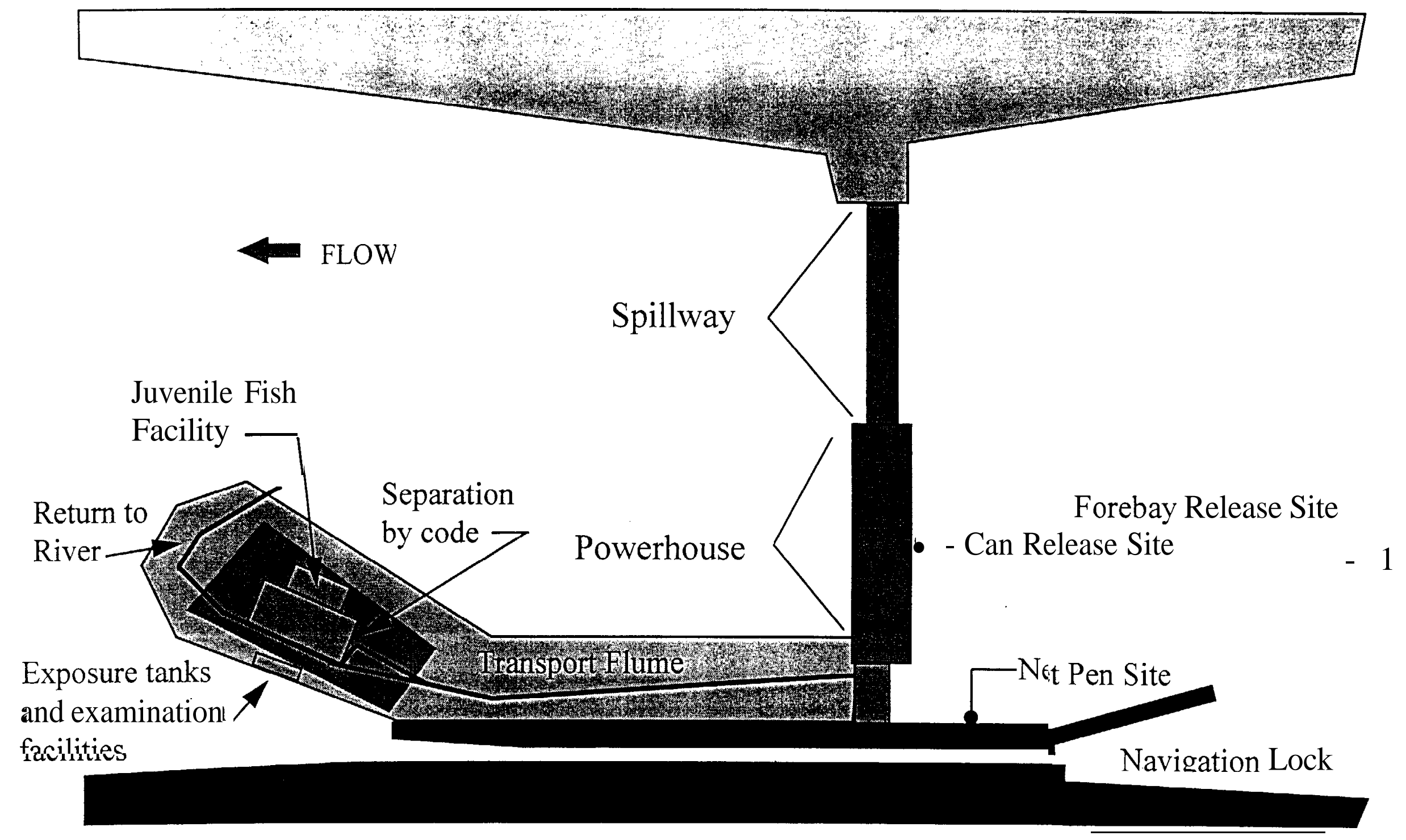

Figure 2. Overhead view of study area at Little Goose Dam, showing release and recapture sites of test fish. 
percent total dissolved gas levels ranged from 113.3 to $115.8 \%$ for the nine replicates (Fig. 3). Typically, total dissolved gas levels were maintained at 117 to $119 \%$ during the first 24 hours and then decreased to about 113-1 14\%, once signs of GBD began to appear on sampled fish,

Both control and treatment fish were held for 55 to 58 hours before examination for signs of GBD, except for the first replicate (held 30 hours). At this time, all treatment fish and a subsample of control fish were anesthetized, then placed in a bath of circulating anesthetic while they were visually examined at 5- to 20-power magnification for subcutaneous emphysema and emboli in all fins, the opercula, head, and eyes. To insure that handling was the same for both conditions, all control fish were anesthetized and handled similarly to treatment fish; but to save effort, only $50 \%$ were examined for signs of GBD. To keep levels of stress to a minimum, all fish were removed from one quarter of a tank for examination before fish were netted from the next quarter.

We found that the thickness of the scales and pigmentation of these feral steelhead smolts caused extreme difficulty in observing emboli in the scale pockets; therefore, examinations of the lateral line were abandoned. Also, examination of emboli in the gill filaments was not done because the necessity for sacrificing fish precluded a before and after evaluation.

During examination of the individual fish, we recorded the severity of emphysema for each fin and operculum by estimating the surface area covered in $5 \%$ increments and the size of the largest emboli in $0.5 \mathrm{~mm}$ increments. All signs of GBD were videotaped, and computer records (time of observation, PIT-tag number, affected body area, severity, and general comments on fish condition) were developed for each fish. 


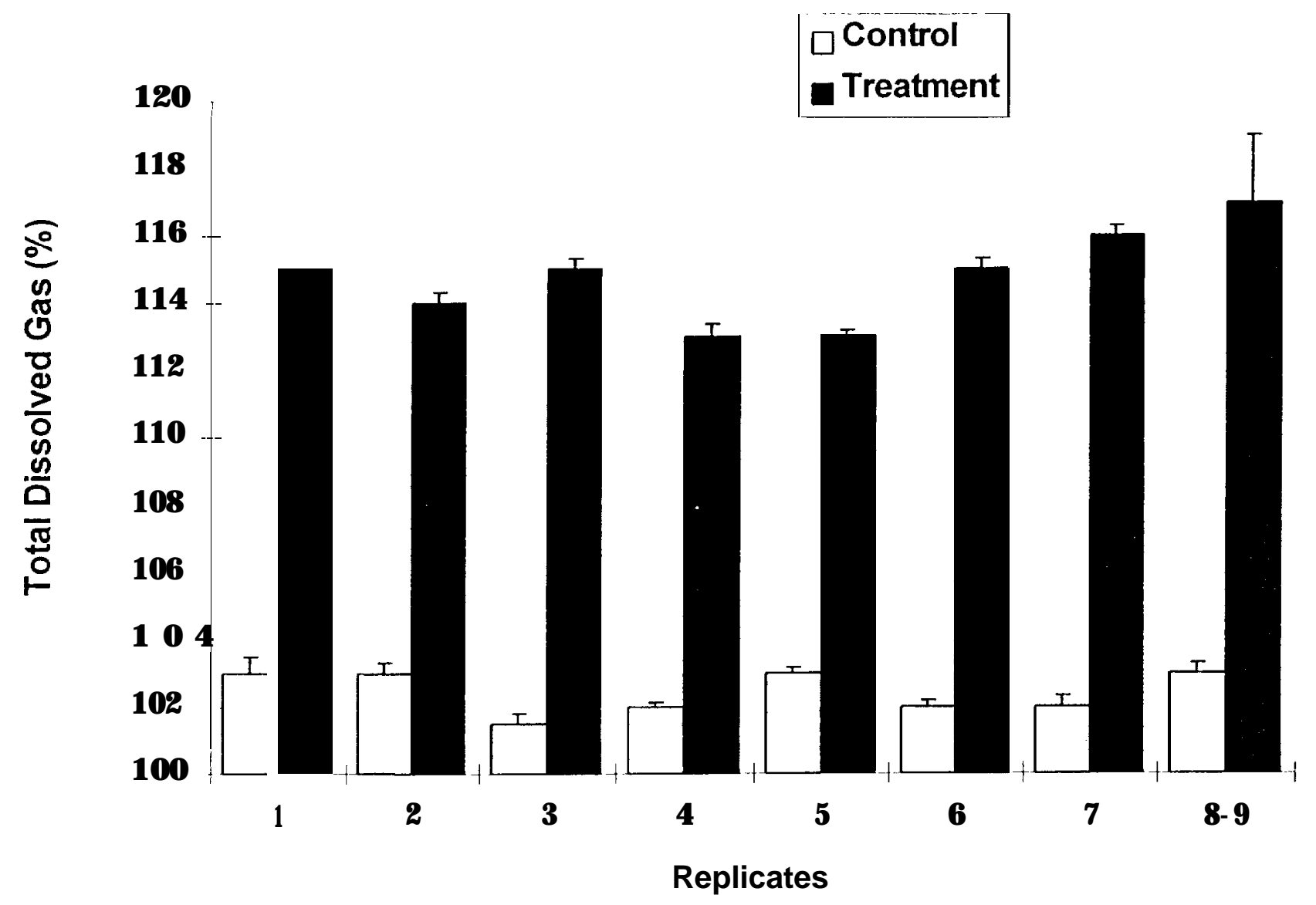

Figure 3. Averaged percent Total Dissolved Gas (TDG) levels and standard errors in treatment and control tanks for Replicates 1-9 (8 and 9 combined). 
After examination, test and control fish were placed in 76-L containers supplemented with oxygen, transported by truck and boat, and released about 400 meters upstream from the Little Goose Dam powerhouse. Since examination of the 750 fish in each replicate required from 3 to 4 hours to complete, multiple releases were made from 1700 to 2100 hours.

The time between release and recapture of test and control fish was greater than anticipated. In an attempt to shorten this time, we made two additional releases of steelhead (Replicates 8 and 9) from a 240-L cylindrical aluminum canister that was designed to release fish at a depth adjacent to the turbine intake. The cylinder was bolted to the outside of the trashrack rake and lowered $19 \mathrm{~m}$ to the ceiling of the turbine intake at elevation $175 \mathrm{~m}$ $(575 \mathrm{ft})$ mean sea level before releasing the fish (Fig. 2). A plastic dome was placed at the top of the canister to trap air, so that fish could gulp air to equilibrate to neutral density at depth before being released. Fish were held at a depth of $19 \mathrm{~m}$ for 5 minutes before release, and all steelhead in these two releases were challenged with supersaturation and had signs of GBD before release.

\section{Estimates of GBD Sign Changes}

The severity of subcutaneous emphysema was indexed by the percentage of fins or body area affected in $20 \%$ increments (i.e. $1-19 \%=1,20-39 \%=2$ etc.), and the size of the largest emboli in $1-\mathrm{mm}$ increments (i.e. $1 \mathrm{~mm}=1,2 \mathrm{~mm}=2$ etc.). The sum of the index number for each affected area was the rank for an individual fish, and rankings at release and recovery were compared for each fish. Video tapes were used to validate the accuracy of the rankings during data analyses. 
To assess the extent of changes in GBD signs during migration through the reservoir, excluding the effect of dam passage, supersaturation-challenged fish were held in a net-pen and evaluated for changes in GBD signs over time. During each test replicate, about 150 PIT-tagged fish challenged with supersaturation were examined and placed in a $2-\mathrm{m}$ by $2.2-\mathrm{m}$ by 5-m-deep net-pen in the forebay (Fig. 2). These fish were divided into groups with and without signs of GBD, and both groups were then sampled and examined for changes in signs every 3 hours for the first 12 hours after release. After the first 12 hours, net-pen fish were examined twice a day during the time that fish were being recaptured in the bypass/collection facility. The experimental design called for mixing of groups with and without signs, but the extra fish handling necessary to acquire fish with signs compromised our ability to make cogent evaluations of sign changes.

To produce a statistically detectable assessment of a 7\% loss of signs caused by dam passage, sample sizes were based on our best assumptions: 50\% prevalence of GBD signs at release, $30 \%$ interception by the traveling screens at Little Goose Dam, 10\% immediate mortality, and $10 \%$ loss of GBD signs in the net-pen or prior to dam passage. Six replicate releases of 300 control and 300 test fish with 150 fish held in the net-pen were used.

\section{Estimates of Relative Survival of Supersaturation Challenged Fish}

PIT-tag interrogation data were obtained from both test and control fish groups as they passed through Little Goose, Lower Monumental, and McNary Dams. The ratio of detections of test to control fish at each of the dams provided an empirical observation of losses due to 
direct and indirect impacts from exposure to TDG supersaturation. Survival of net-pen held fish was used to adjust for latent handling impacts aggravated by GBD.

To evaluate relative survival, we assumed that fish guidance efficiency was equal for both test and control fish. If not, and impacted fish maintained a higher depth distribution than non-impacted fish, then relative survival would have appeared higher for impacted fish. Additionally we speculated that the impacts of experimental exposure to supersaturation would have affected test fish both during migration through Little Goose Forebay and Lower Monumental Reservoir. Thus, the best estimate of relative survival of test fish would be measured at Lower Mounumental and McNary Dams, (excluding the detections at Little Goose Dam).

Assuming interrogation levels of $30 \%$ at Little Goose and Lower Monumental Dams, and $20 \%$ at McNary Dam, six replicates of 300 test and control fish were necessary to statistically detect a $10 \%$ mortality of treatment fish.

\section{RESULTS}

\section{Fish Released Into Forebay}

Nine test replicates were completed in which a total of 1,767 control and 1,623 supersaturation-challenged fish were released. A total of 1,247 fish were recaptured and reexamined at the Little Goose Dam bypass/collection facility (36\% control and 38\% test fish; Table 1). Median passage times from release to recapture for the first seven releases into the 
Table 1. Total numbers of fish released and recovered, percentage with signs of gas bubble disease (GBD), and median times from release to recapture for treatment and control groups for all nine replicates.

\begin{tabular}{|c|c|c|c|c|c|c|c|c|c|c|c|}
\hline \multirow[b]{3}{*}{ Rep } & \multirow[b]{3}{*}{$\begin{array}{c}\text { TDG" } \\
(\%)\end{array}$} & \multicolumn{5}{|c|}{ Controls } & \multicolumn{5}{|c|}{ Treatment } \\
\hline & & \multicolumn{2}{|c|}{ Release } & \multicolumn{3}{|c|}{ Recover } & \multicolumn{2}{|c|}{ R e le a s e } & \multicolumn{3}{|c|}{ Recover } \\
\hline & & $\begin{array}{c}\text { Fish } \\
\text { no. }\end{array}$ & $\begin{array}{c}\mathrm{GBD}^{\mathrm{b}} \\
(\%)\end{array}$ & $\begin{array}{l}\text { Fish } \\
\text { no. }\end{array}$ & $\begin{array}{c}\text { GBD } \\
(\%)\end{array}$ & $\begin{array}{c}\text { Time } \\
\text { h:m }\end{array}$ & $\begin{array}{c}\text { Fish } \\
\text { no. }\end{array}$ & $\begin{array}{c}\text { GBD } \\
(\%)\end{array}$ & $\begin{array}{c}\text { Fish } \\
\text { no. }\end{array}$ & $\begin{array}{c}\text { GBD } \\
(\%)\end{array}$ & $\begin{array}{c}\text { Time } \\
\text { h:m }\end{array}$ \\
\hline 1 & 114 & 130 & 0.0 & 51 & 2.0 & $9: 14$ & 136 & 22.8 & 44 & 4.5 & 7:00 \\
\hline 2 & 124 & 149 & 0.0 & 55 & 3.6 & $4: 35$ & 116 & 16.4 & 37 & 8.1 & $4: 24$ \\
\hline 3 & 128 & 286 & 0.0 & 120 & 5.0 & $4: 14$ & 275 & 23.3 & 118 & 19.5 & $4: 36$ \\
\hline 4 & 119 & 301 & 0.0 & 90 & 7.8 & $13: 18$ & 255 & 51.2 & 82 & 29.3 & $4: 12$ \\
\hline 5 & 114 & 305 & 0.0 & 51 & 7.8 & $7: 14$ & 215 & 28.4 & 58 & 13.8 & $3: 18$ \\
\hline 6 & 115 & 298 & 0.0 & 120 & 0.0 & $4: 54$ & 245 & 40.0 & 96 & 17.7 & $5: 54$ \\
\hline 7 & 122 & 298 & 0.0 & 143 & 0.7 & $12: 06$ & 255 & 31.4 & 127 & 9.5 & $10: 04$ \\
\hline $8^{\circ}$ & 115 & & & & & & 53 & 100 & 22 & 36.4 & $4: 08$ \\
\hline 9 & 117 & & & & & & 73 & 100 & 33 & 33.3 & $5: 30$ \\
\hline Poole & & 1,767 & 0.0 & 630 & 3.3 & $7: 14$ & 1,623 & 37.5 & 617 & 17.5 & $4: 24$ \\
\hline
\end{tabular}

a Average percent TDG in the forebay of Little Goose Dam for the 12 hours following release.

b A $50 \%$ subsample of controls were examined for signs of GBD.

c Releases were made from cylinder directly in front of turbine unit 4. All fish were treatment group fish with signs of GBD.

d Weighted by number of fish examined; time is median time for all replicates. 
forebay ranged from 4.2 to 13.3 hours for control and 4.2 to 10 hours for treatment groups. Median passage time for the two releases made from the canister located directly in front of the powerhouse (Replicates 8 and 9) was 5.8 hours, which was faster than a few of the forebay release groups, but similar to the median time of 6.1 hours for the first seven replicates.

\section{Changes in Prevalence of GBD Signs}

In all nine replicates, the prevalence of external GBD signs in treatment groups released into the forebay decreased following migration to the dam and passage into the turbine intake and through the juvenile bypass/collection facility (Fig. 4). To assess the significance of these decreases, we calculated the percent change in mean prevalence of GBD signs between initial examination and reexamination for all nine replicates (Table 2). This percent change (in all cases a decrease) ranged from 17 to $81 \%$ with a mean of $60.7 \%$ (s.e. $=6.1)$.

The percent change in GBD prevalence was inversely correlated to TDG levels in the forebay $(\mathrm{R}=0.71, \mathrm{P}=.039)($ Fig. 5). The largest decrease in prevalence occurred in Replicate 1 with forebay levels of $114 \%$ TDG, while the smallest decrease occurred in Replicate 3 with forebay levels of $128 \%$. Of treatment fish displaying no GBD signs at release, $5.9 \%$ showed signs at recapture, and $50 \%$ of these fish were from Replicate 3 . 


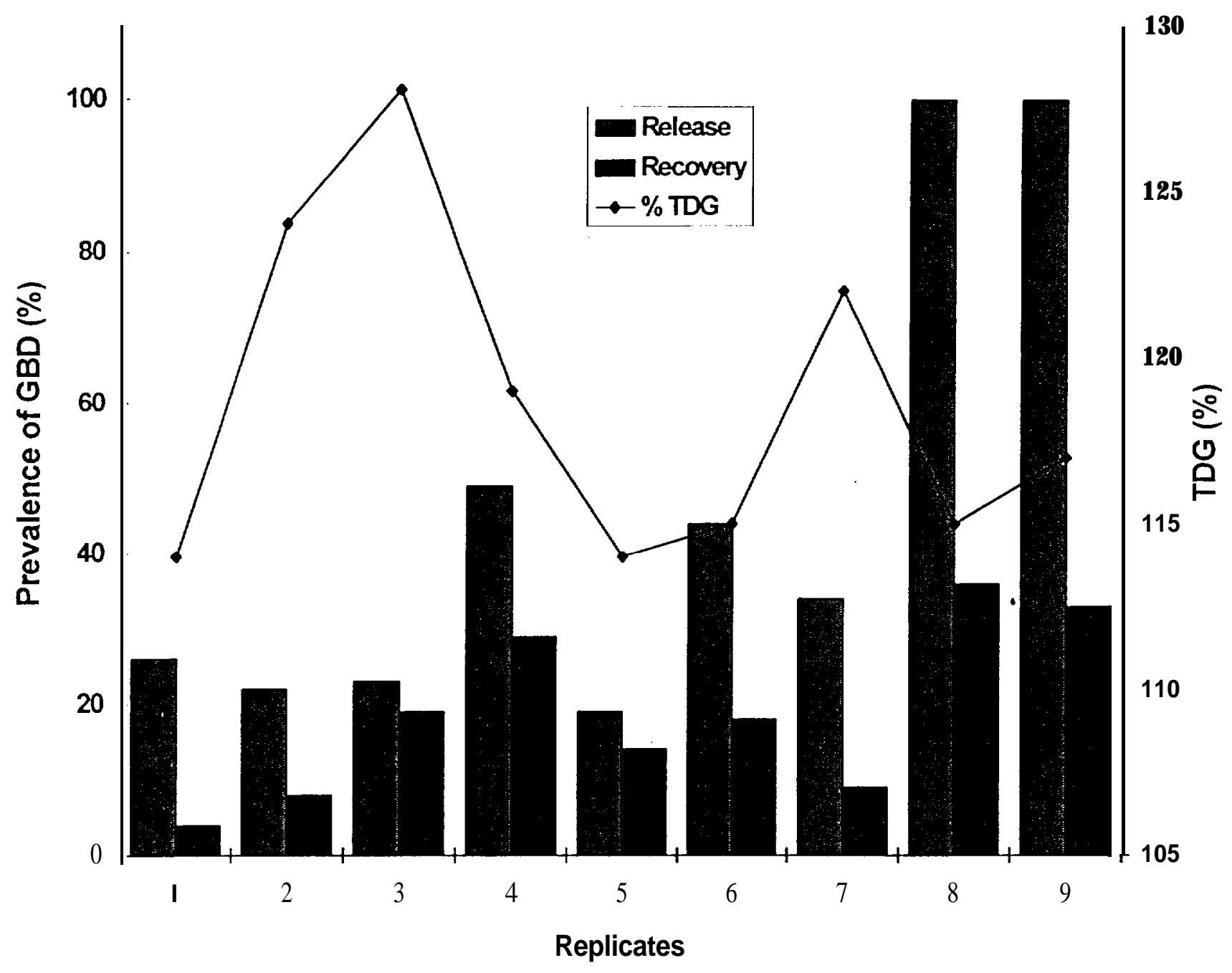

Figure 4. Prevalence of gas bubble disease (GBD) signs at release and recapture and the averaged percent total dissolved gas (TDG) levels in the forebay of Little Goose Dam. 
Table 2. Percent changes in prevalence of GBD signs between release and recapture for forebay release fish and between introduction and reexamination for net-pen fish.

\begin{tabular}{|c|c|c|c|c|c|c|c|c|}
\hline \multirow[t]{2}{*}{ Replicate } & \multicolumn{4}{|c|}{ Forebay releases } & \multicolumn{4}{|c|}{ Net-pen } \\
\hline & $\begin{array}{c}\text { Number } \\
\text { recaptured }\end{array}$ & $\begin{array}{l}\text { Percent } \\
\text { with signs } \\
\text { at release (a) }\end{array}$ & $\begin{array}{c}\text { Percent } \\
\text { with signs } \\
\text { at recapture (b) }\end{array}$ & $\begin{array}{l}\text { Percent } \\
\text { Change } \\
(a-b) / a\end{array}$ & $\begin{array}{l}\text { Number } \\
\text { introduced }\end{array}$ & $\begin{array}{l}\text { Percent } \\
\text { with signs } \\
\text { at intro. (a) }\end{array}$ & $\begin{array}{c}\text { Percent } \\
\text { with signs } \\
\text { at reexam. (b) }\end{array}$ & $\begin{array}{l}\text { Percent } \\
\text { Change } \\
(\mathrm{a}-\mathrm{b}) / \mathrm{a}\end{array}$ \\
\hline 1 & 44 & 26 & 5 & 81 & & & & \\
\hline 2 & 37 & 22 & 8 & 64 & 9 & 100 & 67 & 33 \\
\hline 3 & 119 & 23 & 19 & 17 & 29 & 100 & 93 & 7 \\
\hline 4 & 82 & 49 & 28 & 43 & 51 & 100 & 88 & 12 \\
\hline 5 & 58 & 19 & 7 & 63 & 32 & 100 & 72 & 18 \\
\hline 6 & 96 & 44 & 12 & 73 & 36 & 100 & 69 & 31 \\
\hline 7 & 127 & 34 & 9 & 73 & 28 & 100 & 64 & 36 \\
\hline 8 & 22 & 100 & 32 & 68 & & & & \\
\hline 9 & 33 & 100 & 36 & 64 & & & & \\
\hline Pooled $^{\mathrm{b}}$ & 618 & 38 & 16 & 58 & 188 & 100 & 78 & 22 \\
\hline
\end{tabular}

a Reexamination closest to median passage time was used for analysis.

b Weighted by number of fish examined. 


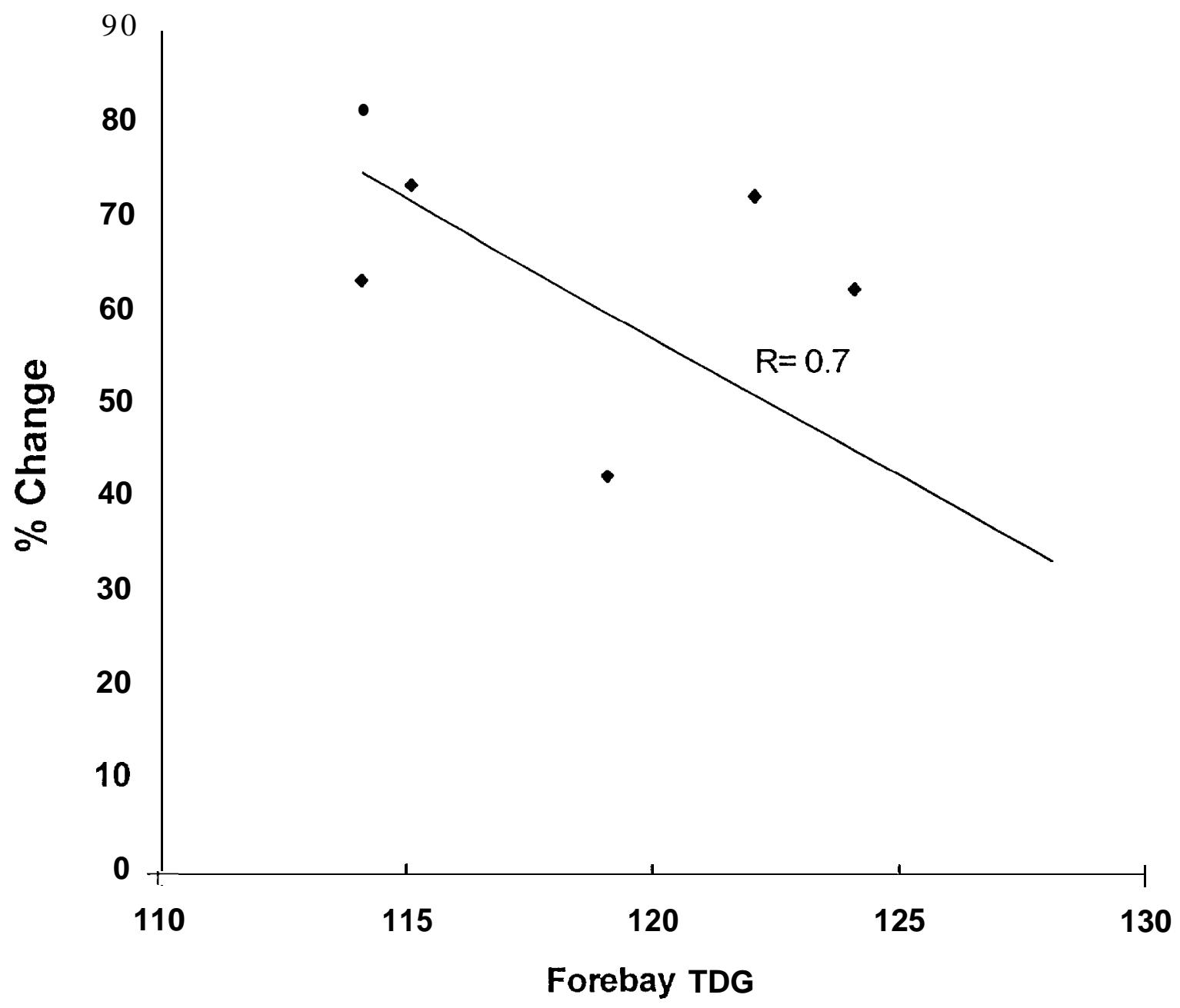

Figure 5. Correlation of percent change in prevalence of gas bubble disease with averaged diassolved levels in the forbay for first seven replicates. 


\section{Changes in Severity of GBD Signs}

Of the 617 fish recaptured that displayed GBD signs at release, 30\% showed a decrease, $66 \%$ showed no change, and $4 \%$ showed an increase in severity of signs. Over $50 \%$ of these increases were also in Replicate 3 (Table 3). Average severity of signs decreased 0.3 index units, from 1.5 to 1.2 , and there was a strong positive correlation $(\mathrm{R}=0.81)$ between time in the forebay and decrease in severity of signs for all replicates combined, including Replicate 3 (Fig. 6).

Of steelhead released with the severity levels of only 1 or $2,67 \%$ lost all signs of GBD at reexamination. As expected, with increased severity level at release, progressively more fish showed decreased severity at recovery; however, progressively less fish lost all signs of GBD (Fig. 7).

\section{Fish Held in Net-Pens}

Of the fish held in net-pens in the forebay of Little Goose Dam, a total of 188 steelhead with signs of GBD and 116 without were examined for changes in prevalence and severity of signs over time. Using results of the examinations closest to median passage time for the forebay releases, the prevalence of signs decreased in all replicates except the first (Table 2). However, the total loss of signs was $22 \%$, approximately half of the loss observed among fish passing into and through the bypass system. As with fish released into the forebay, the smallest decrease in prevalence was in Replicate 3 (100 to 93), when TDG levels reached $128 \%$ in the forebay. Of the 116 steelhead that originally did not have GBD signs, $8 \%$ developed signs, and $44 \%$ of these developments occurred in Replicate 3. 
Table 3. Prevalence and severity of external signs of gas bubble disease (GBD) among juvenile steelhead exposed to high levels of TDG for 3 days then released and recaptured at Little Goose Dam, 1996.

\begin{tabular}{|c|c|c|c|c|c|c|c|c|c|c|c|c|c|}
\hline \multirow[b]{3}{*}{ Replicate } & \multirow{3}{*}{\begin{tabular}{l}
\multicolumn{2}{c}{ Forebay } \\
avg. TDG \\
$\% \quad$ sat.'
\end{tabular}} & \multicolumn{4}{|c|}{ Release } & \multicolumn{7}{|c|}{ Recapture } & \multirow{3}{*}{$\begin{array}{r}\text { Mean } \\
\text { severity } \\
\text { change }\end{array}$} \\
\hline & & Fish & GBD & Severity & index ${ }^{a}$ & \multirow{2}{*}{$\begin{array}{c}\text { Fish } \\
\text { no. }\end{array}$} & \multirow{2}{*}{$\begin{array}{l}\text { GBD } \\
(\%)\end{array}$} & \multicolumn{5}{|c|}{ Severity index } & \\
\hline & & no. & $(\%)$ & Mean & $\mathrm{sd}$ & & & Decrease & Same & Increase & Mean & $\mathrm{sd}$ & \\
\hline 1 & 114 & 136 & 23 & 1.3 & 0.4 & 44 & 4 & 10 & 34 & 0 & 1.0 & 0.0 & -0.3 \\
\hline 2 & 124 & 116 & 16 & 1.4 & 0.5 & 37 & 8 & 3 & 34 & 0 & 1.0 & 0.0 & -0.4 \\
\hline 3 & 128 & 275 & 23 & 1.5 & 0.7 & 118 & 19 & 19 & 85 & 14 & 1.3 & 0.7 & -0.2 \\
\hline 4 & 119 & 255 & 51 & 1.9 & 1.1 & 82 & 29 & 34 & 42 & 6 & 1.5 & 0.9 & -0.4 \\
\hline 5 & 114 & 215 & 28 & 1.4 & 0.7 & 58 & 14 & 9 & 47 & 2 & 1.2 & 0.5 & -0.2 \\
\hline 6 & 115 & 245 & 40 & 1.6 & 1.1 & 96 & 18 & 35 & 59 & 2 & 1.3 & 0.4 & -0.3 \\
\hline 7 & 122 & 255 & 31 & 1.4 & 0.7 & 127 & 9 & 36 & 88 & 3 & 1.0 & 0.0 & -0.4 \\
\hline 8 & 115 & 53 & 100 & 1.2 & 0.4 & 22 & 36 & 16 & 6 & 0 & 1.0 & 0.0 & -0.2 \\
\hline 9 & 117 & 73 & 100 & 1.5 & 1.0 & 33 & 33 & 21 & 12 & 0 & 1.7 & 1.4 & 0.3 \\
\hline Pooled & & 1,623 & 38 & 1.5 & & 617 & 17 & 183 & 407 & 27 & 1.2 & & -0.3 \\
\hline
\end{tabular}

a Severity index calculated using increments of $20 \%$ coverage of fins or operculum and 1-mm bubble diameter. For reexamined fish, number of individuals are identified for which signs decreased, show no change, or increased.

b Average percent TDG for the 12 hours following release.

c Weighted by numbers of fish examined. 

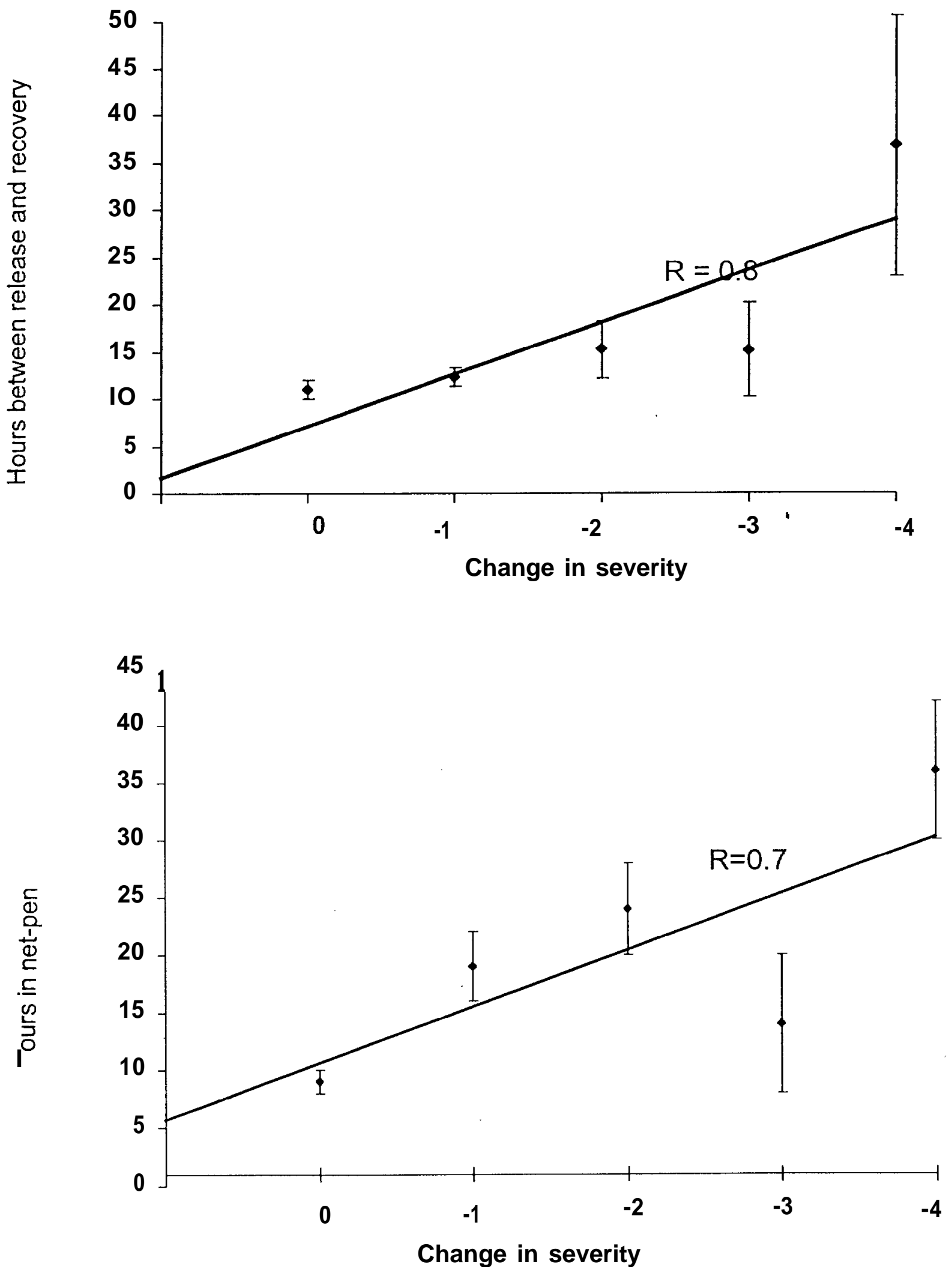

Figure 6. Correlation of hours between release and recovery (or time in net-pen) with change in severity of GBD symptoms. 


\section{Forebay-released fish}

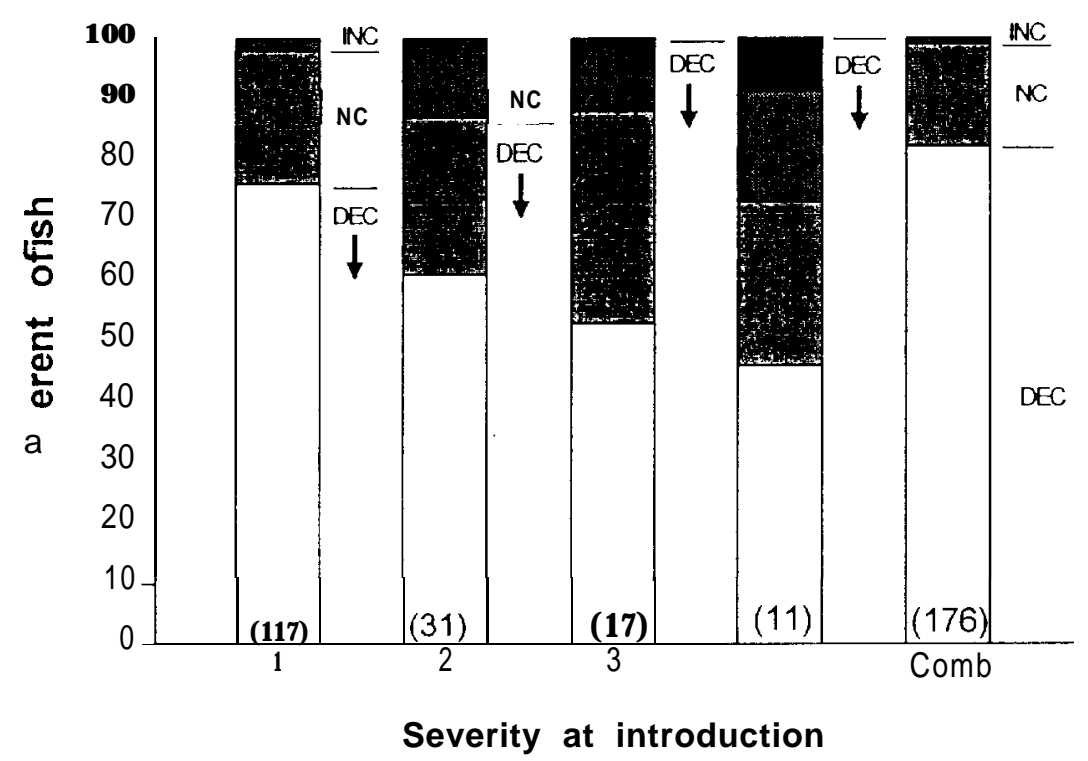

Severity at reexamination

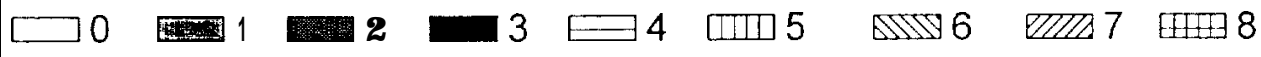

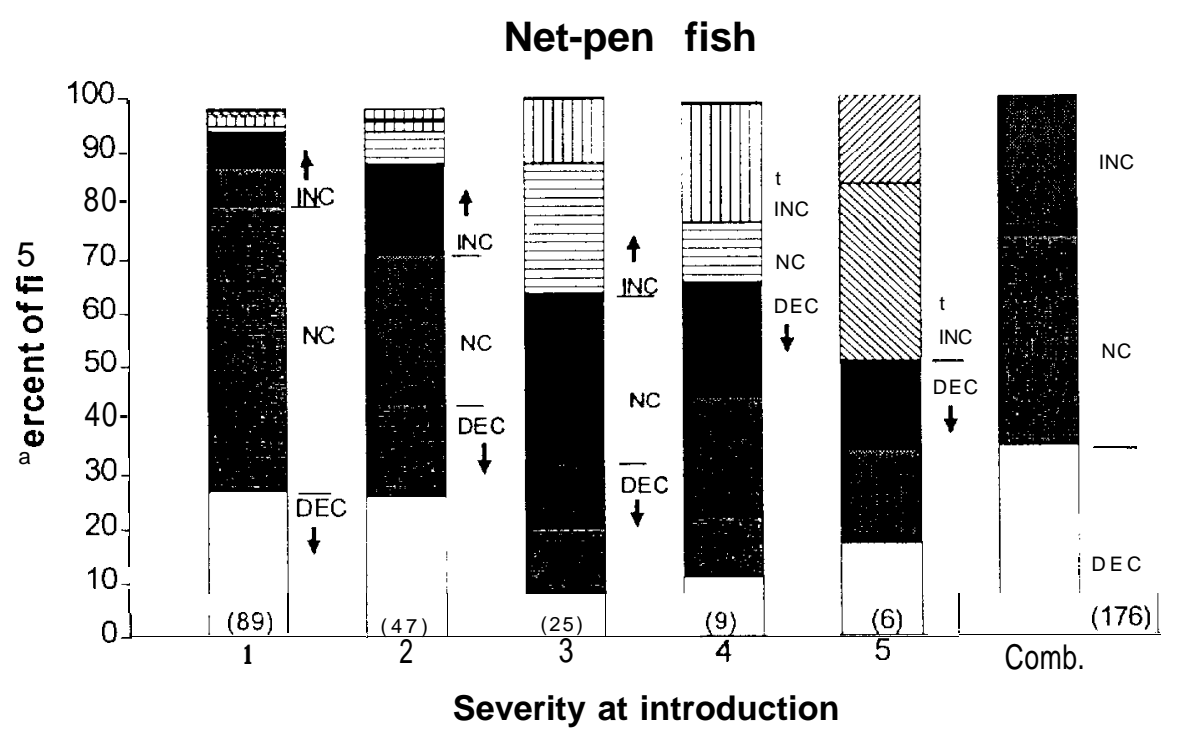

Figure 7. Percentage of forebay-released or net-pen held fish at each level of severity at reexamination, categorized by levels of seventy at introduction. Numbers in parenthesis are total number of fish examined. For the combined bar (comb.), seventy at reexamination is categorized only by increase(INC), no change (NC), or decrease (DEC), not by severity level. 
The average severity of GBD signs decreased 0.2 index units (compared to 0.3 for the forebay releases; Table 4). These changes in severity were directly but only mildly correlated with TDG levels in the forebay $(\mathrm{R}=0.7)$; the only large increase in severity was also in Replicate 3. Generally, changes in severity for net-pen fish were comparable to those of the forebay releases; i.e. with increased severity level at initiation of holding, progressively more fish showed decreased severity at reexamination (Fig 7). However, while $24 \%$ of the net-pen fish displayed an increase in severity of signs, only $4 \%$ of the forebay fish did.

\section{Changes in Relative Survival During Migration}

Based on recoveries of PIT-tagged steelhead at Little Goose, Lower Monumental, and McNary Dams, mean relative survival estimates for the seven supersaturation-challenged treatment groups ranged from 0.913 to 1.072 , and averaged 0.964 (s. e. 0.024) (Table 5). Since the $95 \%$ confidence interval for this ratio included one, no statistical difference in survival was detected between the treatment and control groups.

We speculated that the effects of experimental exposure to supersaturation would have had the largest impact on test fish both during migration through Little Goose Dam forebay and Lower Monumental Reservoir, and therefore the best estimate of relative survival of test

fish would be measured at Lower Mounumental and McNary Dams. However, an analysis of the data without detections at Little Goose Dam still showed no difference in survival between test and control fish. 
Table 4. Prevalence and severity of external signs of GBD among juvenile steelhead exposed to high levels of TDG for 3 days, then held in net-pens in the forebay of Little Goose Darn, 1996.

\begin{tabular}{|c|c|c|c|c|c|c|c|c|c|c|c|c|}
\hline \multirow[b]{3}{*}{ Replicate } & \multirow{3}{*}{$\begin{array}{c}\text { Forebay } \\
\text { avg. TDG } \\
(\%)^{\mathrm{c}}\end{array}$} & \multicolumn{4}{|c|}{ Introduction } & \multicolumn{6}{|c|}{ Reexamination ${ }^{\mathbf{a}}$} & \multirow{3}{*}{$\begin{array}{c}\text { Mean } \\
\text { severity } \\
\text { change }\end{array}$} \\
\hline & & \multirow{2}{*}{$\begin{array}{c}\text { Fish } \\
\text { no. }\end{array}$} & \multirow{2}{*}{$\begin{array}{c}\text { GBD } \\
(\%)\end{array}$} & \multicolumn{2}{|c|}{ Severity index ${ }^{b}$} & \multirow{2}{*}{$\begin{array}{r}\text { Prev. } \\
(\%)\end{array}$} & \multicolumn{5}{|c|}{ Severity index } & \\
\hline & & & & Mean & $\mathrm{sd}$ & & Decrease & Same & Increase & Mean & $\mathrm{sd}$ & \\
\hline 1 & 114 & 3 & 100 & 1.7 & 1.1 & 100 & 1 & 2 & 0 & 1.3 & 0.6 & -0.3 \\
\hline 2 & 124 & 9 & 100 & 1.1 & 0.3 & 67 & 3 & 4 & 2 & 1.1 & 1.2 & 0.0 \\
\hline 3 & 128 & 29 & 100 & 1.8 & 1.0 & 93 & 6 & 11 & 12 & 2.6 & 2.1 & 0.8 \\
\hline 4 & 119 & 51 & 100 & 3.2 & 2.8 & 88 & 14 & 15 & 22 & 3.3. & 2.7 & 0.1 \\
\hline 5 & 114 & 32 & 100 & 1.5 & 0.8 & 72 & 11 & 15 & 6 & 1.4 & 1.1 & -0.1 \\
\hline 6 & 115 & 36 & 100 & 2.3 & 1.7 & 69 & 20 & 15 & 1 & 1.3 & 1.8 & -1.0 \\
\hline 7 & 122 & 28 & 100 & 2.0 & 1.5 & 64 & 14 & 11 & 3 & 1.0 & 1.0 & -1.0 \\
\hline Pooled $^{d}$ & & 188 & 100 & 2.2 & 1.9 & 78 & 69 & 73 & 46 & 2.0 & 2.1 & -0.2 \\
\hline
\end{tabular}

${ }^{a}$ Net-pen reexamination closest to time of median passage was used for analysis.

${ }^{b}$ Severity index calculated using increments of $20 \%$ coverage of fins or operculum and 1-mm bubble diameter. For reexamined fish, number of individuals are identified for which signs decreased, showed no change, or increased.

${ }^{c}$ Average percent TDG for the $12 \mathrm{~h}$ following release.

${ }^{\mathrm{d}}$ Weighted by numbers of fish examined. 
Table 5. Percent detections and relative survival estimates (test to control ratios) of Pittagged steelhead released in the forebay of Little Goose Dam and detected downstream at Little Goose, Lower Monumental, McNary, John Day, and Bonneville Dams.

\begin{tabular}{|c|c|c|c|c|c|c|c|c|}
\hline \multirow[b]{2}{*}{ Replicate } & \multirow[b]{2}{*}{ Group } & \multirow[b]{2}{*}{$\begin{array}{c}\text { Release } \\
\text { date }\end{array}$} & \multirow[b]{2}{*}{$\begin{array}{c}\text { Release } \\
\text { no. }\end{array}$} & & \multicolumn{4}{|c|}{ Relative recoveries } \\
\hline & & & & & $\begin{array}{c}\text { No. } \\
\text { detected }\end{array}$ & $\begin{array}{c}\% \\
\text { detected. }\end{array}$ & $\mathrm{T} / \mathrm{C} "$ & s.e. \\
\hline I & Treatment & $5 / 15$ & 131 & & 92 & 0.702 & & \\
\hline 1 & Control & $5 / 15$ & 126 & & 83 & 0.659 & 1.066 & 0.091 \\
\hline 2 & Treatment & $5 / 18$ & 115 & & 91 & 0.791 & & \\
\hline 2 & Control & $5 / 18$ & 145 & & 107 & 0.738 & 1.072 & 0.074 \\
\hline 3 & Treatment & $5 / 21$ & 272 & & 196 & 0.721 & & \\
\hline 3 & Control & $5 / 21$ & 283 & & 211 & 0.746 & 0.966 & 0.060 \\
\hline 4 & Treatment & $5 / 24$ & 249 & & 173 & 0.695 & & \\
\hline 4 & Control & $5 / 24$ & 290 & & 212 & 0.731 & 0.950 & 0.052 \\
\hline 5 & Treatment & $5 / 27$ & 212 & & 135 & 0.637 & & \\
\hline 5 & Control & $5 / 27$ & 305 & & 209 & 0.685 & 0.929 & 0.060 \\
\hline 6 & Treatment & $6 / 03$ & 245 & & 107 & 0.437 & & \\
\hline 6 & Control & $6 / 03$ & 297 & & 129 & 0.434 & 1.007 & 0.099 \\
\hline 7 & Treatment & $6 / 06$ & 255 & & 181 & 0.710 & & \\
\hline 7 & Control & $6 / 06$ & 29 & 6 & 230 & 0.777 & 0.913 & 0.045 \\
\hline \multirow[t]{2}{*}{ Pooled } & Treatment & & 1479 & & 975 & .659 & & \\
\hline & Control & & 1742 & & 1181 & ,678 & 0.972 & 0.024 \\
\hline
\end{tabular}

" $\mathrm{T} / \mathrm{C}=$ test to control ratio. 


\section{DISCUSSION}

Prevalence and severity of GBD signs decreased in both forebay-released and net-pen held fish. To some degree, this was expected because test fish were exposed to dissolved gas levels sufficiently high to generate a high prevalence of GBD signs. Test fish were then placed in the forebay or in a 5-m-deep net-pen, where the available depth allowed depth compensation for supersaturated conditions. Decreases in severity and prevalence of signs were directly but only mildly related to time between release and recapture (passage time) and were related inversely to TDG levels in the forebay. The experimental design was developed to minimize passage time by releasing steelhead in the evening during the time of peak migration. However, times to recapture were substantially longer than anticipated. Since passage times of canister-released fish (released directly in front of the powerhouse) were similar to those of forebay-released fish (released $400 \mathrm{~m}$ upstream from the dam), we surmise that time from release to the turbine intake and gatewell entry was a small portion of the passage time.

Median passage times were similar to the 4.9 hours reported by Monk et al. (1997) for steelhead that were released in the gatewell and passed through the bypass/collection system at Lower Granite Dam. They also reported that fish released into the collection channel passed through the bypass/collection system without delay. Based on these separate observations, we speculated that the longest delay in passage for our test fish occurred in the gatewells at Little Goose Dam.

The decrease in prevalence of GBD signs was significantly greater for the forebayreleased groups compared to the net-pen fish $(58 \%$ and $22 \%$, respectively; $\mathbf{P}=\mathbf{0 . 0 1})$. With 
all severity levels combined, $96 \%$ of forebay-released fish either showed no change or a decrease in severity; this was true for only $65 \%$ of net-pen fish $(35 \%$ showed a increase in signs) (Fig. 7). The dissolved gas exposure experienced by forebay-released and net-pen fish was probably dissimilar because of dissimilar water depths maintained by free-swimming and captive fish. Therefore, because of the length of time for passage through the system, it was difficult to separate the effects of hydrostatic pressure during dam passage on GBD signs from the effects of depth distribution during reservoir and gatewell residence. Little is known about depth distribution of steelhead in gatewells.

Following experimental exposure to supersaturation, test fish often had GBD signs which were more severe than those most commonly seen on juvenile salmonids examined from the river. Thus, we did not relate changes observed among fish with severe GBD signs to possible changes among fish examined at dams during periods when severity of signs was low. However, observations of bubble collapse and growth for fish displaying low-severity signs properly equate to changes which would be observed in years with low spill volumes.

The exclusive use of juvenile steelhead for these tests may have resulted in a conservative estimate for decreases in survival associated with a GBD insult during migration. Recent results from laboratory tests of juvenile salmon suggested greater predation by northern squawfish for fish exposed to dissolved gas supersaturation than for unexposed cohorts (Matthew Mesa, USGS-Biological Resources Division, Cook Wash., Pers. commun., April, 1996.) However, compared with juvenile salmon migrants, the greater size and speed of steelhead may decrease predation by fish and birds. Prey consumption data for northern 
squawfish (Ptychocheilus oregonensis) in John Day Reservoir, described by Poe et al. (1988), supports this speculation for piscivores.

\section{CONCLUSIONS AND RECOMMENDATIONS}

Additional tests are necessary to separate the effects of hydrostatic pressure during dam passage on GBD signs from the effects of depth distribution during reservoir residence on GBD signs. Thus, quicker recovery of fish passing through the dam will be necessary. Because fish size may be of significant importance to predation rates, smaller juvenile salmon must also be used in a similar GBD challenge test to confirm that survival is not decreased. 


\section{REFERENCES}

Ebel, W. J. , H. L. Raymond, G. E. Monan, W. E. Farr, and G. K. Tanonaka. 1975. Effects of atmospheric gas supersaturation caused by dams on salmon and steelhead trout of the Snake and Columbia Rivers. (Available from Northwest Fisheries Science Center, 2725 Montlake Blvd. E., Seattle, WA 98112-2097.)

GBDTWG Inspection Team, 1995. Research priorities related to Gas bubble Monitoring needs in the Columbia River Basin. September 1995. 19 p. (Available from Northwest Fisheries Science Center, 2725 Montlake Blvd. E., Seattle, WA 98112-2097.)

Monk, B. H., B. P. Sandford, and Douglas B. Dey. 1997. Evaluation of orifice passage efficiency and descaling with an extended-length bar screen, new vertical barrier screen, and inlet flow vane at Lower Granite Dam, 1995. Report to U.S. Army Corps of Engineers, Delivery Order E86950104, 19 p. plus Appendices. (Available from Northwest Fisheries Science Center, 2725 Montlake Blvd. E., Seattle, WA 98112-2097.)

Montgomery Watson. 1995. Bubble reabsorption in a simulated smolt bypass system -Concept Assessments. Report to Bonneville Power Administration, Contract No. DEAC79-93BP66208, (Available from Bonneville Power Administration, Portland OR 97208.)

NMFS. Working Group on Gas Bubble Disease. 1994. Recommendations. 10 p. (Available from Northwest Fisheries Science Center, 2725 Montlake Blvd. E., Seattle, WA 98 1122097.)

NMFS. Working Group on Gas Bubble Disease. 1996. Summary report, third working group meeting. April 1996. 33 p. plus Appendices. (Available from Northwest Fisheries Science Center, 2725 Montlake Blvd. E., Seattle, WA 98112-2097.)

Poe, T. P., H. C. Hansel, S. Vigg, D. E. Palmer, and L. A. Prendergast. 1988. Predation by northern squawfish, Walleye, smallmouth bass, and channel catfish in a mainstem Columbia River Reservoir: Feeding ecology during the salmonid smolt out-migration. Final report to Bonneville Power Administration, Contract No. DE-AI79-82BP34796, Project No. 82-3. (Available from Bonneville Power Administration, Portland OR 97208.)

Weber, D. D. and M. H. Schiewe. 1976. Morphology and function of the lateral line of juvenile steelhead trout in relation to gas-bubble disease. J. Fish Biol. 9:217-233. 